\title{
ESTRUTURA DO ESCUDO SUL-BRASILEIRO: UMA REVISÃO ATRAVÉS DE DADOS GRAVIMÉTRICOS E MAGNETOMÉTRICOS
}

\author{
STEPHEN E. HALLINAN*, MARTA S.M. MANTOVANI*, WLADIMIR SHUKOWSKY* e \\ IRALDO BRAGGION Jr*
}

\begin{abstract}
STRUCTURE OF S-BRAZILIAN SHIELD: A REVISION FROM GRAVITY AND MAGNETIC DATA. New gravity data in southern Brazil are combined with previous data in Brazil and Uruguay, permitting detailed analysis of the basement structure. The Brasiliano cycle tectonic frameworks suggested by previous geological and geophysical studies are tested. Pre-Brasilianp structure (Transamazonian cycle), however, is an importam and hitherto unstated source of lateral density contrast responsible for distinctive gravity discontinuities. Gravity anomalies associated with Mesozoic magmatism are also discordant within the Brasiliano structure, and can also be distinguished by strong accompanying magnetic anomalies. Individual blocks within the Rio de La Plata craton are recognised and a new block, the Paso de los Toros Block, is defmed. The continuation of the Rio de La Plata Craton into Brazil is challenged. The possibly related pre-Brasiliano Nico Perez Terrane (strongly reworked during the Brasiliano) forms the basement to the Rio Grande do Sul Shield, at least to the west of the Pelotas Batholith. Residual isostatic gravity anomalies suggest the continuation of the Ribeira Belt from Paraná State to Rio Grande do Sul. The Curitiba Massif, however, does not. The Luis Alves Complex does continue at least partially towards the south, but its presence beneath the Rio Grande do Sul shield cannot be demonstrated by gravimetric data. The Internai Domain of the Santa Catarina part of the Dom Feliciano Belt can be traced to the Costeiro Granitoid Belt to the north, and is tentatively proposed to lie off the eastern seaboard in Rio Grande do Sul and Uruguay, but is no longer thought to correlate with the Pelotas Batholith. In this scenario, could the Brusque Group metasediments be linked to the Rocha Group?
\end{abstract}

Keywords: Gravity anomalies, crustal structures, tectonic framework.

\begin{abstract}
RESUMO Aos dados gravimétricos existentes no sul do Brasil e no Uruguai, foram adicionados novos dados que permitiram efetuar análise detalhada das estruturas do embasamento. Os arcaboucos tectônicos sugeridos por estudos geológicos e geofísicos anteriores foram testados por meio do conjunto de dados gravimétricos. As estruturas Pré-Brasilianas (Ciclo Transamazônico) mostraram ser fonte de contraste lateral de densidade, responsáveis por descontinuidades gravimétricas distintas. As anomalias gravimétricas associadas ao magmatismo Mesozóico também são discordantes com as estruturas brasilianas e podem também ser identificadas por intermédio das fortes anomalias magnéticas associadas. São reconhecidos blocos individuais do Craton Rio de La Plata, e define-se novo bloco, aqui denominado de Bloco Paso de Los Toros. O terreno prébrasiliano Nico Perez (fortemente retrabalhado no Brasiliano), definido no Uruguai, pelo menos a oeste do Batólito de Pelotas, forma o embasamento do Escudo Sul-Rio-Grandense. A amplificação do sinal após a eliminação das anomalias isostáticas sugere possível continuação do Cinturão Ribeira até o Rio Grande do Sul, o que não é válido para o Maciço de Curitiba. O complexo Luís Alves continua parcialmente para o sul, entretanto sua presença sob o escudo gaúcho não pode ser demonstrada pêlos dados gravimétricos. O Domínio Interno do Cinturão Dom Feliciano, em Santa Catarina, pode ser traçado até o Cinturão Granitóide Costeiro, ao norte, sendo que, ao sul, não se correlacionaria ao Batólito de Pelotas, mas poderia ter continuidade a leste do mesmo, na margem continental. Neste cenário, o Grupo Brusque não poderia estar relacionado ao Grupo Rocha?
\end{abstract}

Palavras-chave: Anomalias gravimétricas, estruturas crustais, arcabouço tectônico.

INTRODUÇÃO A geologia do pré-cambriano exposto no sul do Brasil e Uruguai aflora em duas áreas distintas: uma área setentrional no litoral dos Estados de São Paulo, Paraná e Santa Catarina, e uma área meridional no Rio Grande do Sul e no Uruguai, separadas pela cobertura Fanerozóica da Bacia do Paraná (Fig. 1, compilação das Figs. 2 e 3, linhas da espessura da bacia seguindo Zalán et al. 1988). As unidades estruturais se aglutinaram durante $o$ Ciclo Brasiliano no Proterozóico Superior - Cambriano Inferior, relacionado com o período final da formação do Gondwana ocidental (Almeida et al. 1973), contemporâneo com o Ciclo Pan-Africano no continente Africano (Porada 1979, 1991). Observam-se cinturões deformados separando blocos relativamente estáveis. Vários estudos buscaram verificar a continuação física das estruturas entre ambas as regiões, tendo sido propostas diversas correlações. Um dos principais debates trata a continuação do Craton Pré-Brasiliano Rio de La Plata (atualmente aflorando no Uruguai), no Rio Grande do Sul, estendendo-se até o Complexo Luis Alves, na área setentrional (e.g., Fragoso César, 1980,1991,
Brito Neves \& Cordani 1991), enquanto outros autores preferem tratar os afloramentos pré-Brasilianos como independentes (e.g., Basei 1985). A proposta existência, ou não, do Cinturão Ribeira (a nordeste do Complexo Luis Alves) no Escudo Sul-Rio-Grandense (Fragoso César 1991) e a continuação do Cinturão Dom Feliciano entre as duas áreas (Fragoso César 1980, Fragoso César et al. 1987, Basei 1985) ainda estão em aberto. Interpretando dados gravimétricos, Shukowsky et al. (1991) sugeriram a continuação do Cinturão Dom Feliciano e a continuidade entre o Complexo Luis Alves e o Craton Rio de La Plata, mas não aquela do Cinturão Ribeira, preferindo correlacionar as rochas ocidentais do Escudo Sul-Rio-Grandense com o Maciço de Curitiba.

Neste trabalho, os dados gravimétricos são reavaliados em vista de (1) adição de mais de 800 novas estações gravimétricas medidas em 1992, (2) eliminação de anomalias devido ao relevo isostático na Moho, destacando-se as anomalias ligadas às estruturas crustais, (3) avaliação preliminar de dados magnetométricos e (4) estudos sobre a es- 


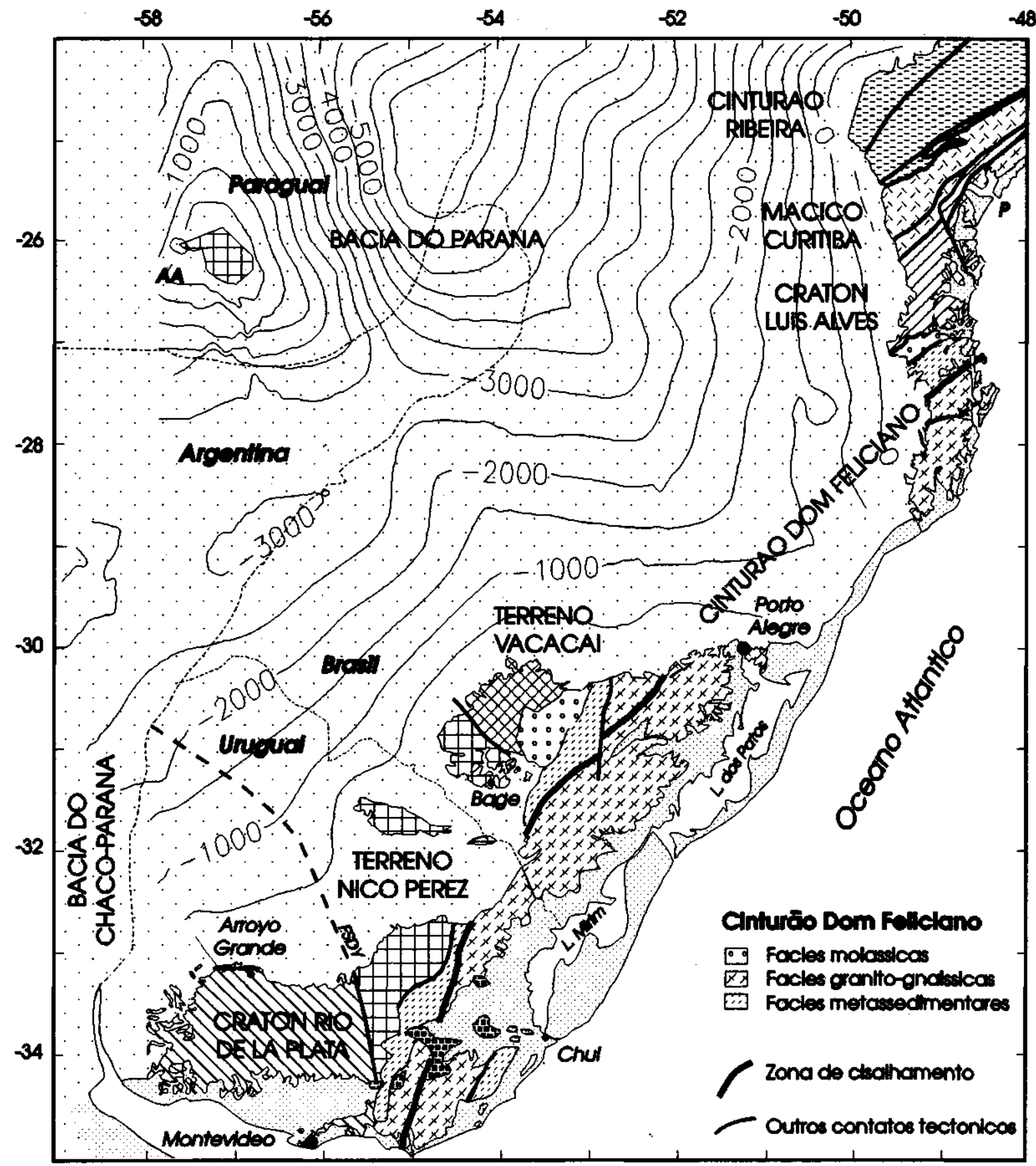

Lavas Mezozólcos do Grea de Lagoa Mirm

Fanerozólco $\square$ Rochas de cobertura do Fanerazólco Supertor nỏo diferenclados Secimentos e vulcanicas
de Bacia do Parańs

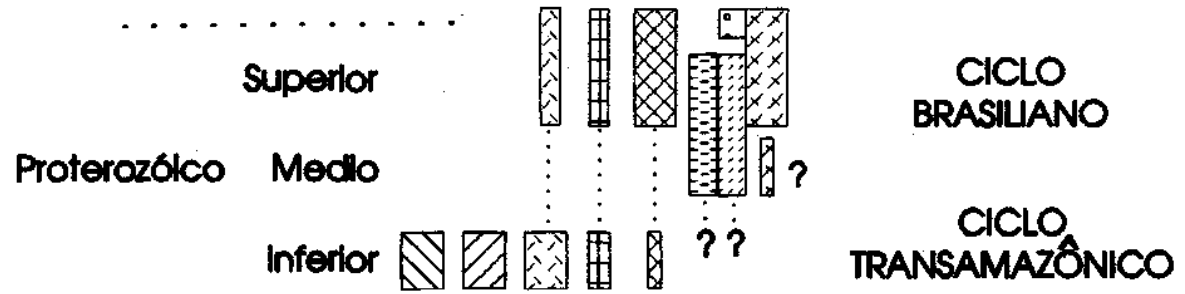

Figura 1 -Esquema geológico do Sul do Brasil e Uruguai, onde se destacam duas exposições do embasamento, separadas pelas rochas de cobertura da Bacia do Paraná. As relações estratigráficas entre as principais unidades estruturais são assinaladas. $(\boldsymbol{A} \boldsymbol{A}=$ Arco de Assunção, $\boldsymbol{P}=$ Pontal do Sul - Paranaguá $; \boldsymbol{F S D Y}=$ Falha dei Sarandi dei Yí)

Figure 1 - Geológica! sketch map of southem Brazil and Uruguay, showing the two basement exposure áreas separated by cover rocks of the Paraná Basin. Key shows approximate stratigraphic relationships between major structural units. See text for sources. (AA = Asunción Are, $\mathbf{P}=$ Pontal do Sul - Paranaguá; FSDY Falha dei Sarandi dei Yí) 


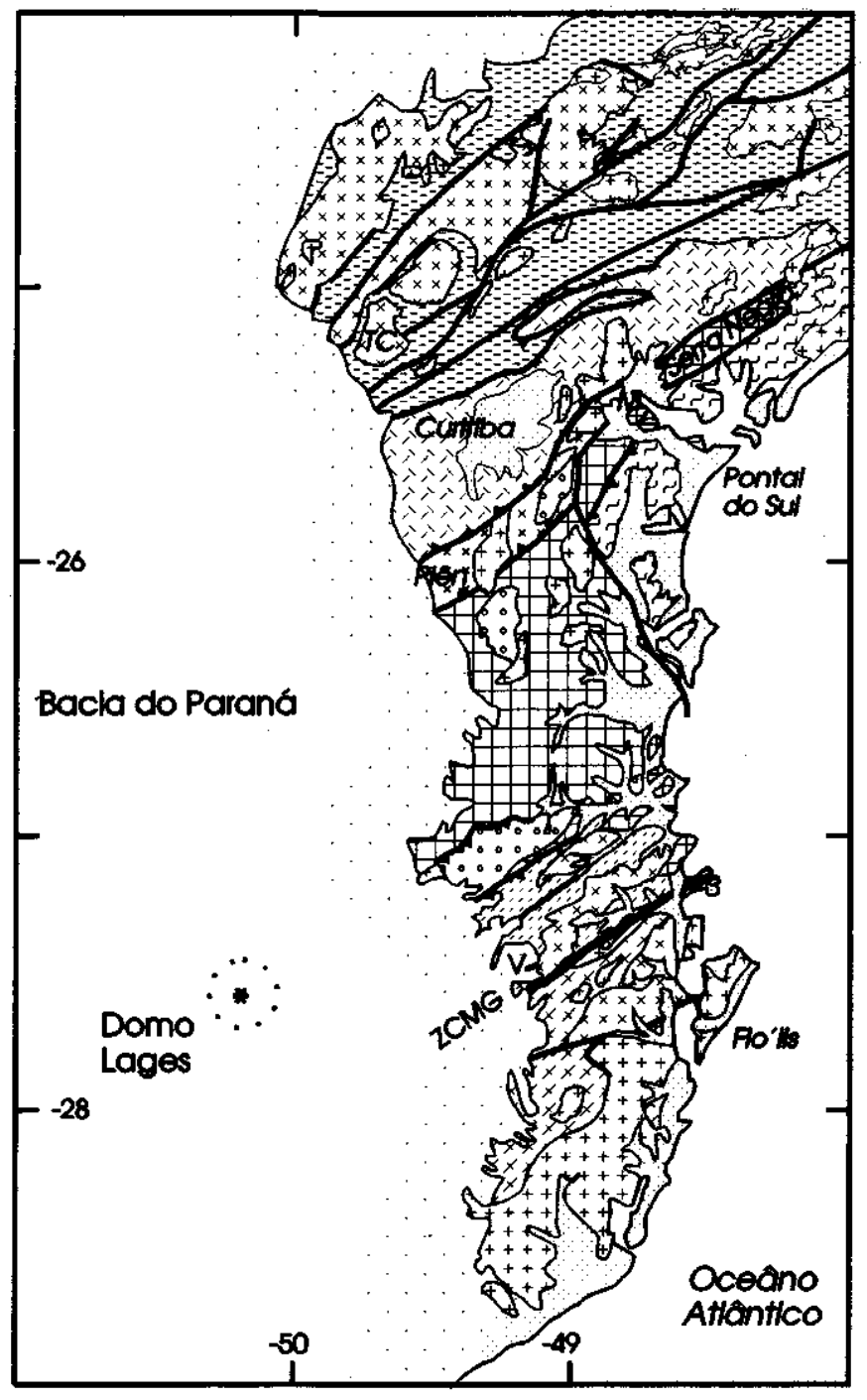

Cobertura Cenoźsica

Cobertura da Bocla do Parano

TERRENOS DOCICLO BRASILIANO

Gronitos
Q Molaso

Metcsecimentos do

Cinturdo Rubelra

Metcosedimentos do

Cinturoo Doin Fellclono

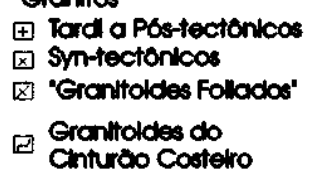

TERRENOS PRÉ-BRASILIANOS

ffl Complexo Luís Alves

13 Maciço Curitiba

Figura 2- Geologia simplificada da porção setentrional do embasamento (PR, SC e pane de SP). As referências encontram-se no texto. $(\boldsymbol{V}=$ Granito Valsungana, $\boldsymbol{T C}=$ Granito Três Córregos, ZCMG = Zona de cisalhamento de Major Gercino)

Figure 2 - Geological summary of the northern basement área (PR, SC \& a part of SP). See text for sources. $(\mathbf{V}=$ Valsungana granite, $\mathbf{T C}=$ Três Córregos granite, $\mathbf{Z C M G}=$ Major Gercino Shear Zone)

pessura litosférica efetiva da área meridional (Shukowsky et al. 1993, Mantovani et al. 1993). Embora as interpretações de dados gravimétricos não sejam unívocas, podem ser utilizadas para discriminar modelos geológicos conflitantes, abundantes para essa região. As interpretações aqui sugeridas por testes quantitativos têm também o intuito de provocar debates sobre a compartimentação tectônica, para direcionar pesquisas adicionais.
GEOLOGIA REGIONAL O mapa geológico da margem costeira de parte dos Estados de São Paulo, Paraná e Santa Catarina (Fig. 2) foi compilado de Awdziesj et al. (1986), Basei (1985), Basei et al. (1991), Biondi et al (1989), Janasi \& Ulbrich $(1991,1992)$ e Mantovani et al. (1989, 1991), e aquele das porções do Uruguai e do Rio Grande do Sul (Fig. 3) por Dália Salda et al. (1988), Preciozzi et al. (1980), Bossi e Campal (1991), Santos et al (1989), Fragoso César (1980, 1991), Fragoso César et al (1987) e Fernandes et al (1990, 1992).

Na porção setentrional (Fig. 2), o Complexo Luis Alves (seguindo o Complexo Granulítico de Santa Catarina, de Hartmann et al 1979a, b, e o segmento cratônico de Luis Alves, de Kaul \& Teixeira, 1982) serviu de antepaís durante o Ciclo Brasiliano, sobreposto pelo Cinturão Dom Feliciano na margem meridional, pelo Maciço de Curitiba e Cinturão Ribeira (Hasui et al 1975, Basei et al 1991), na margem setentrional, e pelo Cinturão Granitóide Costeiro, a leste (Basei et al 1991). Esse complexo é predominantemente composto de granulitos e ortognaisses, tendo sido retrabaIhado no Proterozóico Inferior. A tendência estrutural interna corresponde a um forte bandamento NW contrastando com a tendência geral NE dos cinturões do Proterozóico Superior que o circunscrevem. Núcleos de complexos granulíticos correlacionados, de idades Pré-Brasilianas, são observados na área de Serra Negra (NE da Fig. 2), continuando no Estado de São Paulo (Kaul \& Teixeira 1982).

$\mathrm{Na}$ porção maior do embasamento exposto (Fig. 3, Estado do Rio Grande do Sul, Brasil e Uruguai), o Cráton Rio de La Plata atuou como antepaís do Cinturão Dom Feliciano (Fragoso César 1980), mas a ocorrência deste cráton no Brasil, como surgerido por Fragoso César (1980) e Brito Neves \& Cordani (1991), é discutível (ver abaixo). O Cráton Rio de La Plata é composto por uma grande área central de gnaisses graníticos de fácies anfibolito separando os menores afloramentos vulcano-sedimentares de baixo grau, ao norte (Arroio Grande) e ao sul (Paso Severino e Montevideo), que possivelmente formam um terreno de rochas verdes - granito (Fragoso César 1980, Fragoso César \& Soliani 1984). As idades são geralmente do Proterozóico Inferior, mas pelo menos a margem oriental sofreu retrabalhamento durante o Ciclo Brasiliano. Essa área foi denominada recentemente de Terreno Nico Perez (Bossi \& Campal 1992).

A estrutura fortemente ESE no cráton (Bossi 1983) contrasta um pouco com o bandamento NW típico do Terreno Nico Perez, situado ao nordeste da zona de falha de Sarandí dei Yí (FSDY, Fig. 3). O Terreno Nico Perez é composto de áreas granulíticas (de Santa Maria Chico no Brasil, Nardi \& Hartmann 1979; e de Valentines, no Uruguai, Ferrando \& Fernandez 1971) e áreas gnáissico-granito-migmatíticas de fácies xisto verde-anfibolito (os Gnaisses Bagé, de Fragoso César 1991). O Terreno Vacacaí (Fragoso César 1991), ao norte da falha (transcorrente) de Ibaré, compreende gnaisses do Proterozóico Superior (Gnaisses Cambai), sequências vulcano-sedimentares e lâminas ultramáficas importantes (interpretado como ofiolítos), intrudido por granitos de idade brasiliana. Idades pré-brasilianas neste terreno estão restritas aos blocos granulíticos exóticos, preservados em alguns gnaisses e correlacionados (possivelmente) com os granulitos de Santa Maria Chico expostos no Terreno Nico Perez (Soliani 1986, Fragoso César 1991).

A presença de granulitos do Proterozóico Inferior, nessa área meridional, estimulou sua correlação com os granulitos do Complexo Luis Alves, motivando Fragoso César \& Soliani (1984) a considerar o Complexo Luis Alves como sendo a extremidade norte do Cráton Rio de La Plata, cenário subsequentemente adotado em algumas sínteses regionais (p. ex., Brito Neves \& Cordani 1992). Entretanto, essa correlação é mitigada pela evidência de retrabalhamento de grande escala do Terreno Nico Perez, como evidenciado 


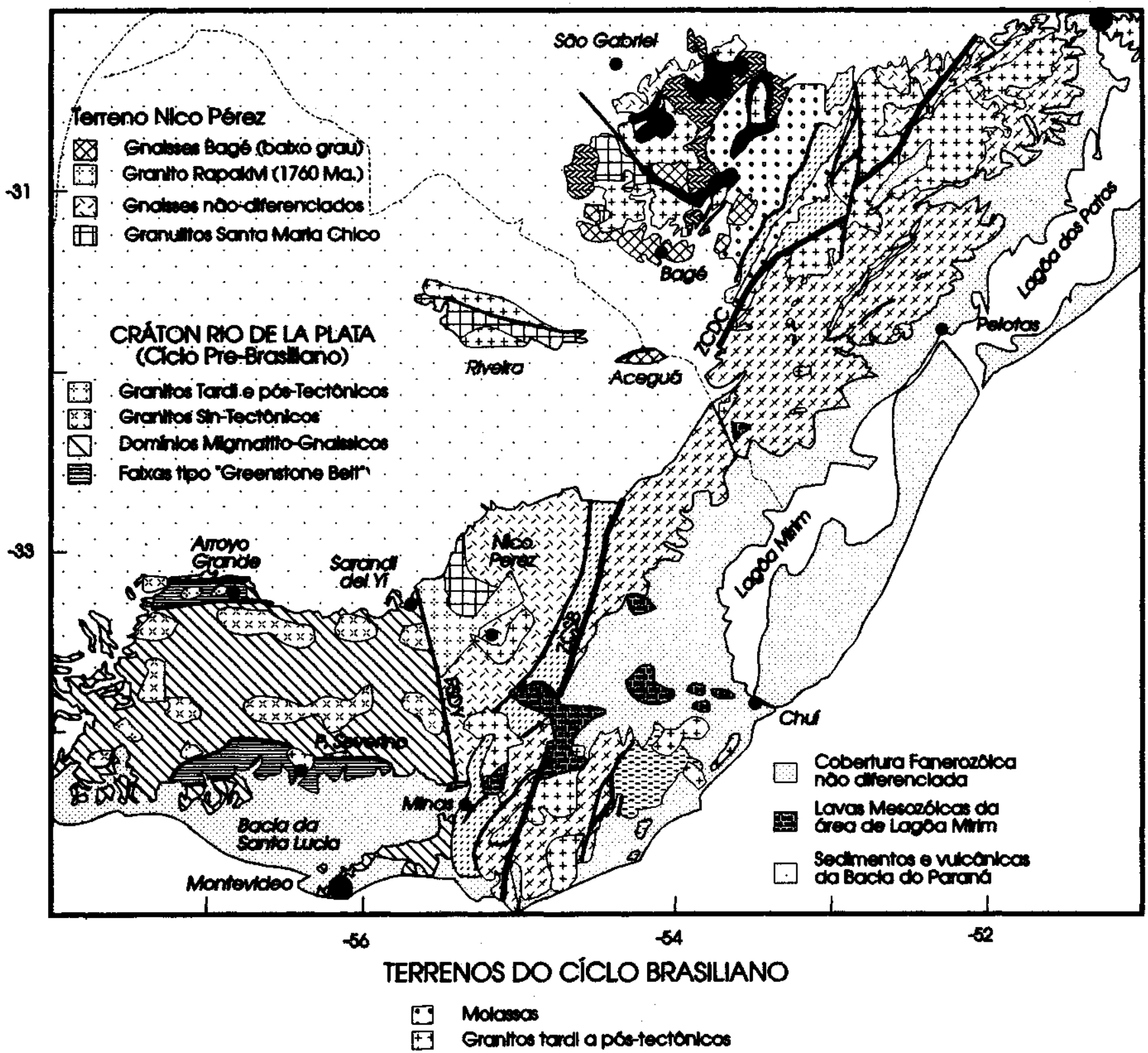

\section{Cinturoo Dom Fellokno \\ Q7 Gnolseses do Batoltito Pelotas

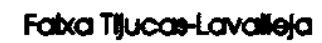 \\ Enpo Rocha}

[.] Enclases pré-Brasilanos ??

Figura 3 - Geologia simplificada da porção meridional do embasamento (RS \& RU). As referências encontram-se no texto. (FSDY = Falha de Sarandi dei Yi, $\boldsymbol{Z C S B}=$ Zona de Cisalhamento Sierra Ballena $; \boldsymbol{Z C D C}=$ Zona de Cisalhamento Dorsal do Canguçu)

Figure 3 - Geological summary of the southern basement área (RS \& RU). See text for sources. (FSDY = Sarandi dei Yí Fault; ZCSB = Sierra Ballena Shear Zone; $\mathbf{Z C D C}=$ Dorsal do Canguçu Shear Zone)

pelo número crescente de idades do Proterozóico Superior e Cambriano Inferior para os granitos nessa área (Soliani 1986, Cordani \& Soliani 1990), o que não é observado nas mesmas proporções para o Complexo Luis Alves (Basei 1985).

O Cinturão Dom Feliciano, no Rio Grande do Sul e Uruguai, foi descrito por Fragoso César (1980) e Fragoso César et al (1987) e, em Santa Catarina, por Basei (1985). A vergência estrutural nesse cinturão indicou para esses auto- res um transporte para NW em Santa Catarina, e WNW no Rio Grande do Sul e Uruguai, isto é, em direção aos complexos do ante-país.

- Basei (1985) dividiu o afloramento de Santa Catarina em três domínios, correspondendo a porções componentes de um arco colisional. Um Domínio Interno compreendendo os primeiros granitos foliados e migmatitos (as raízes do arco postulado): a Suíte de Granitóides Foliados em Santa Catarina, supostamente litoestratigraficamente equivalentes 
aos gnaisses e migmatitos do Batólito de Pelotas (Rio Grande do Sul, Fragoso César et al 1986), e rochas semelhantes às da Zona Central de Fragoso César et al. (1987), no Uruguai.

- O Domínio Intermediário, caracterizado por metassupracrustais (depósitos pré-colisionais da margem continental): o Grupo Brusque (Santa Catarina), o Cinturão Tijucas (Rio Grande do Sul) e o Grupo Lavalleja (Uruguai). Fragmentos do embasamento reconhecidos nesse domínio são lascas granulíticas do Bloco Luis Alves, em Santa Catarina, os Gnaisses Encantadas - no Rio Grande do Sul - e gnaisses indiferenciados - no Uruguai.

- O Domínio Externo, correspondente a depósitos de molassa colisionais: o Grupo Itajaí (Santa Catarina), o Grupo Camaquã (Rio Grande do Sul) e a Formação Barriga Negra (Uruguai).

Adicionalmente, no Uruguai, observa-se o Grupo Rocha, zona de metassupracrustais na porção oriental, o qual não se apresenta exposto no Brasil. Essa unidade é litologicamente semelhante ao Grupo Lavalleja, incluindo as lascas de gnaisses do embasamento, mas difere na vergência, que é dirigida para SE, distanciando-se do Cráton Rio de La Plata. Granitos sin e pós-tectônicos do Cinturão Dom Feliciano distribuem-se pêlos Domínios Interno e Intermediário, enquanto os depósitos molássicos são intrudidos somente por granitos pós-tectônicos. Uma importante zona de cisalhamento tardia do Ciclo Brasiliano separa o Domínio Interno do Intermediário: a falha de Major Gercino (Santa Catarina Bitencourt et al 1989, Passarem' et al 1993), a Zona de Cisalhamento Dorsal de Canguçu (Rio Grande do Sul; Picada, 1971, Fernandes et al 1992) e a Zona de Cisalhamento Sierra Ballena (Uruguai - Fragoso César et al 1987). O Cinturão Granitóide Costeiro (também denominado Batólito de Paranaguá) compreende algumas gerações de granitos pórfiros cálcio-alcalinos do Ciclo Brasiliano tardio, com orientação NE (Basei et al. 1991). Estruturas do tipo nappe indicam cavalgamento sobre o Complexo Luis Alves, e esses granitóides podem representar a continuação dos terrenos do Complexo Costeiro, que se estendem desde o o sul da Bahia até o Rio Grande do Sul, possivelmente até o Uruguai (Basei et al 1991).

Basei et al (1991) separaram os gnaisses granulíticos e anfibolíticos do Maciço de Curitiba, de idade proterozóica inferior, daqueles do Complexo Luis Alves, devido ao intenso retrabalhamento verificado no primeiro, durante o Brasiliano. A separação entre os dois é marcada pela limitada ocorrência de rochas ultramáficas, cuja afinidade não foi comprovada (Machiavelli 1991), e por uma zona de granitos foliados de idade brasiliana, demonstrando vergência S SE, gerada durante a subducção do Complexo Luis Alves sob a "microplaca" do Maciço de Curitiba, segundo Basei et al (1991). O Cinturão Ribeira é a unidade tectônica da extremidade noroeste dessa área em estudo; compreende o Cinturão Dobrado Apiaí, composto de rochas vulcano-sedimentares de médio a baixo grau, intrudido por granitos sin e póstectônicos do Ciclo Brasiliano (Hasui et al 1975, Campanha et al 1987), e cavalga na direção SE sobre o Maciço de Curitiba.

O significado do Terreno Vacacaí no Rio Grande do Sul é objeto de recentes debates. Sua suposta vergência predominante para leste induziu Fragoso César (1991) a sugerir que essa região é análoga àquela do Cinturão Ribeira no sul, enquanto Shukowsky et al (1991) optaram por correlação entre o Maciço de Curitiba e as porções mais ocidentais deste terreno (os gnaisses migmatíticos de Cambai e as ultramáficas), e Fernandes et al (1992) consideram o terreno como produto do fechamento de um back-arc (o Arco II) durante o colisão do arco oriental (o Arco I, correspondendo ao Batólito Pelotas de Fragoso César et al. 1986) com o Cráton Rio de Ia Plata.
O comportamento estrutural das unidades acima mencionadas e a continuação física dos diversos domínios entre as áreas setentrional e meridional serão discutidos com base nos dados geofísicos disponíveis.

REDUÇÃO DOS DADOS GRAVIMÉTRICOS Durante o ano de 1992, foram adicionadas 829 novas estações gravimétricas ao conjunto de dados existentes no Paraná, Santa Catarina e Rio Grande do Sul (a distribuição de todos os dados utilizados neste estudo é mostrada na figura 4, destacando os dados levantados para este estudo; veja Shukowsky et al 1991, para detalhes dos dados existentes antes de 1992).

Adicionalmente, foram incluídos dados não-publicados e levantados na região de Blumenau, Santa Catarina (CPRM) e Caçapava do Sul, Rio Grande do Sul (António Flavio Costa, CPRM/UFRGS). A excelente cobertura de dados gravimétricos do Uruguai (Servicio Geográfico Militar, República Oriental dei Uruguay, 1973), que não exige qualquer complementação, foi adicionada para fins de examinar esta parte do Escudo Sul-Brasiliense.

A medida de gravidade foi feita com gravímetros La Coste \& Romberg, Modelo-G, e as coordenadas foram determinadas utilizando-se receptores de posicionamento por satélite (Global Positioning System - GPS). A altitude das estações foi medida com altímetros barométricos corrigidos para temperatura e umidade, utilizando-se o método da base fixa, e referidas a pontos da rede de nivelamento do IBGE. As anomalias Bouguer simples foram calculadas utilizandose a Fórmula Internacional da Gravidade de 1967 e o valor padrão de densidade de redução de 2670 kg.nr ${ }^{3}$ (Fig. 4). Os erros no valor de gravidade observado são inferiores a 0.1 mGal. Vários dos pontos de altitude barométrica foram remedidos e apresentaram erros inferiores a $3 \mathrm{~m}$, o que corresponde a incerteza na anomalia Bouguer inferior a 0.6 $\mathrm{mGal}$.

Não foram feitas as correções de terreno em vista da falta de um banco de dados altimétricos digitalizados convenientemente. Shukowsky et al (1987) mostraram que, em áreas com topografia comparável à de São Paulo, 99\% das correções são inferiores a $2 \mathrm{mGal}$, ou seja, inferiores ao intervalo das curvas de contorno de $5 \mathrm{mGal}$ nas figuras aqui apresentadas. De outro lado, os erros provenientes da ausência das correções de terreno são importantes em áreas de topografia íngreme, como por exemplo em correspondência às escarpas da Serra do Mar, (Fig. 5, dado National Geophysical Data Centre, E.U.A., malha de 5'), devendo-se levar em conta essas incertezas na interpretação (ver discussão abaixo).

As anomalias Bouguer simples apresentam valores negativos nas regiões de alta topografia (como demonstrado por Shukowsky et al 1991, nessa região), sugerindo que a topografia é compensada isostaticamente (pelo menos parcialmente) por "raizes crustais" na Moho. As anomalias isostáticas, de comprimento de onda maior, dificultam a busca de anomalias relacionados às feições intercrustais. Para remover o efeito, é necessário entender o tipo de compensação responsável (ver Forsyth 1985, para discussão completa). No caso de isostasia local (Airy Isostasy), a rigidez assumida para a litosfera (ou em outros termos a espessura elástica efetiva) é nula, situação considerada pouco provável numa área relativamente estável, sendo o carregamento topográfico inteiramente compensado na Moho. No caso de compensação (parcial), existindo rigidez na placa litosférica, a natureza do relevo isostático na Moho depende do valor de rigidez da placa: menos rígida $=$ compensação mais local. A espessura elástica é função da tectônica atual, do passado geológico da área e da idade do último evento térmico/orogênico. No continente Norte-Americano, por exemplo, os valores de espessura elástica efetiva variam entre $\sim 4 \mathrm{~km}$, na área de Basin \& Range (em atividade distensional), a 


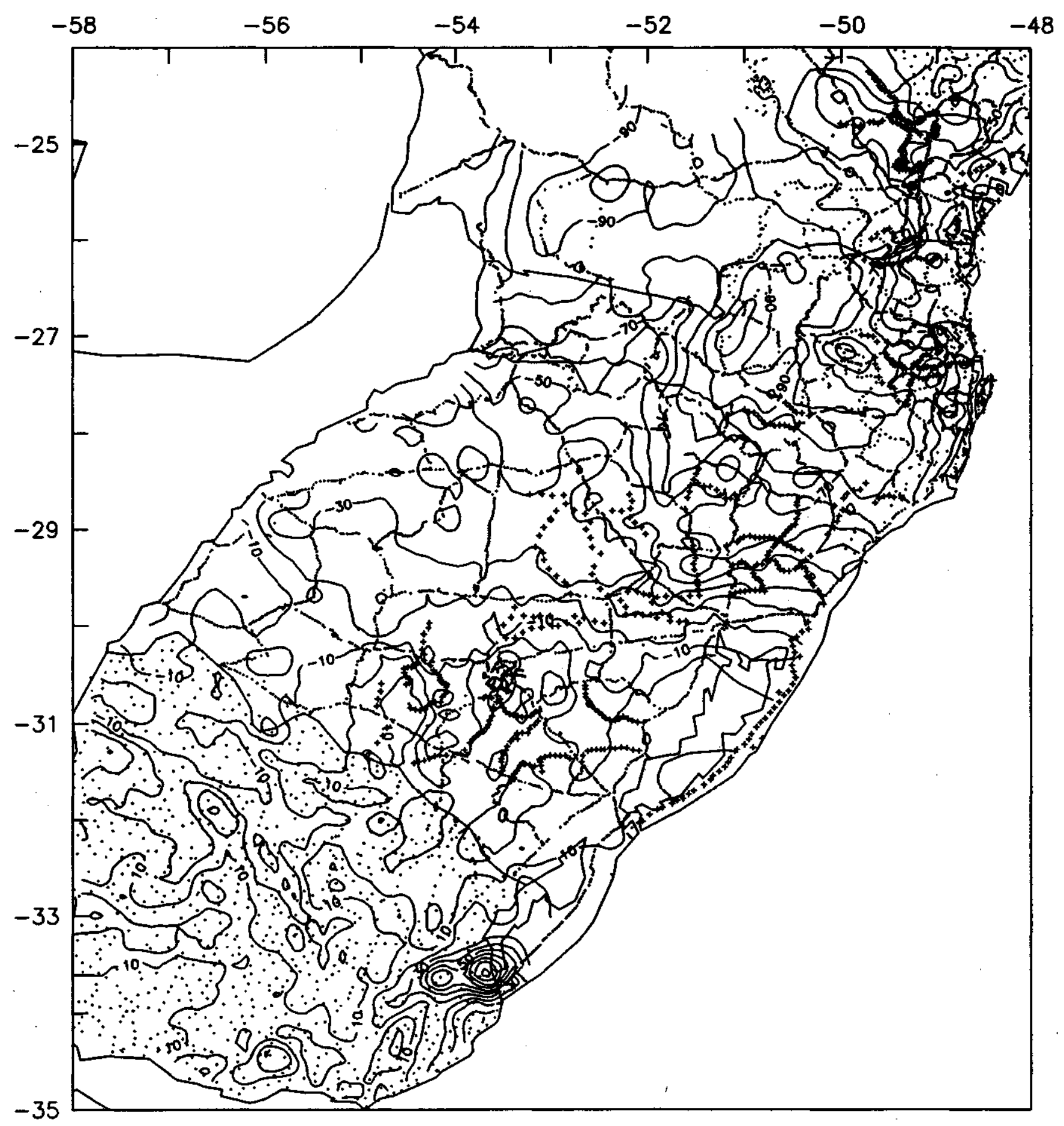

Figura 4 - Localização das estações gravimétricas, distinguindo-se aquelas levantadas anteriormente a 1992 (pontos) daquelas referentes a esse estudo (cruzes). Note-se a diferença na distribuição dos pontos do Brasil em comparação ao Uruguai

Figure 4 - Station locations, distinguishing pre-1992 data (dots) and 1992 data from this study (cresses). Notice different station distribution in Brasil and Uruguay

$>100 \mathrm{~km}$, no Escudo Canadense no interior do continente (Bechtel et al 1990).

Para calcular o relevo na Moho, devido ao carregamento topográfico, foi utilizado o método de Banks et al. (1977); as anomalias gravimétricas causadas por este relevo foram calculadas segundo o método de Parker (1972). Foram assumidas espessuras elásticas de 20,60 e $95 \mathrm{~km}$, sendo o menor valor - aquele sugerido por Karner \& Watts (1982) - para uma margem continental passiva do tipo Atlântico e, o valor maior - aquele calculado por Mantovani et al (1993) - para o Cráton Rio de La Plata a essas latitudes; no cálculo, foi assumida espessura crustal média (nível de compensação) de $35 \mathrm{~km}$. Para evitar os efeitos de borda comum nesse tipo de análise, utilizou-se área maior (Fig. 5), reduzindo-a posteriormente ao tamanho da área em estudo. Foi utilizada uma malha de $0,25^{\circ}$, para o cálculo do relevo da Moho (Fig. 6) e das anomalias gravimétricas isostáticas associadas à Moho. Comparando-se a anomalia isostática calculada para os três valores de espessura elástica considerados, observase variação apenas na amplitude, mantendo-se a forma 


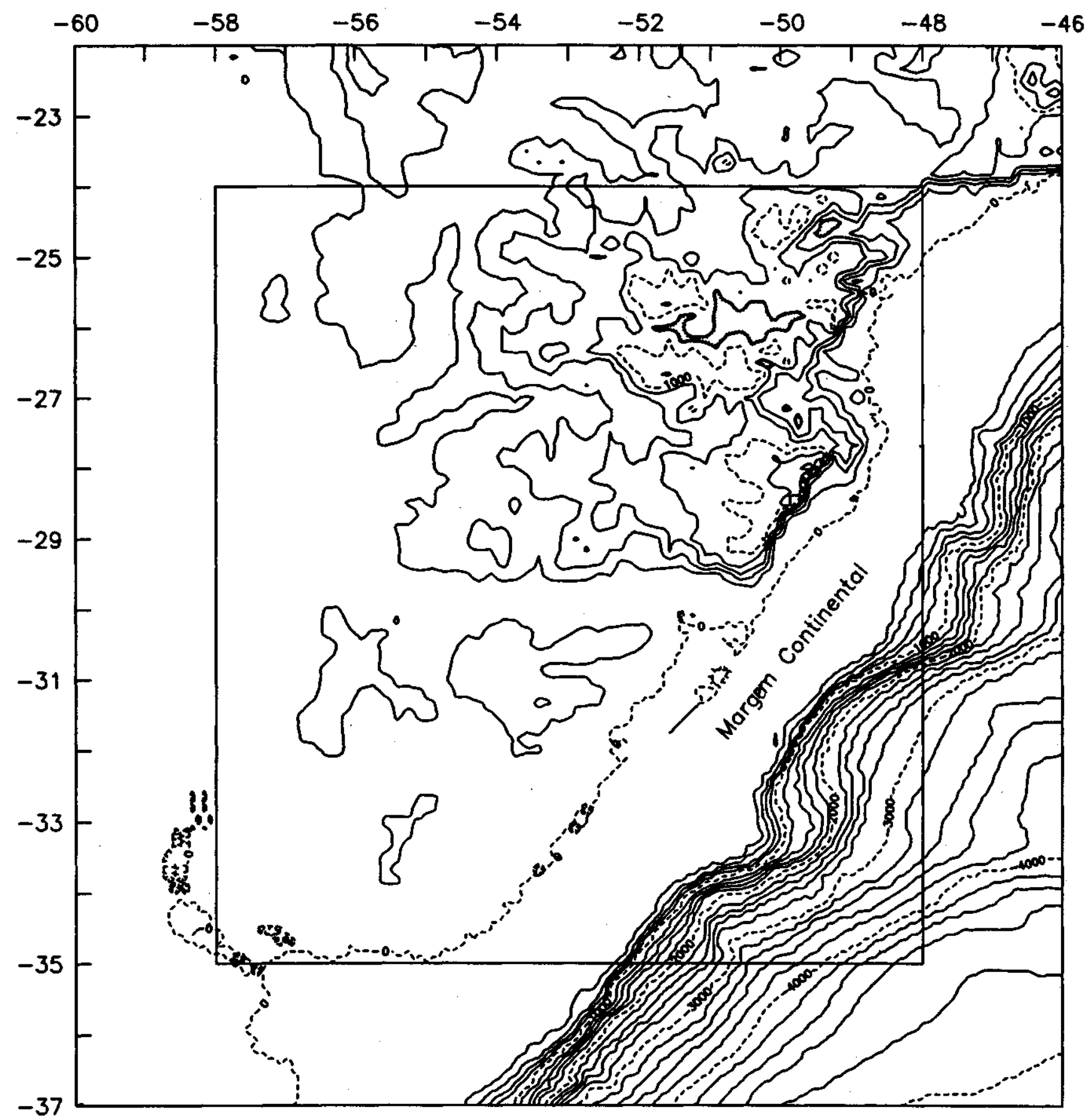

Figura 5 - Topografia (contornos a cada 200 m). Os dados são do National Geophysical Data Base, Washington. É mostrada a área de estudo; a área maior foi utilizada para o cálculo do relevo da Moho e das anomalias isostáticas da gravidade, para evitar efeitos de borda (veja Fig. 6)

Figure 5 - Topography (200 m contours). Data from National Geophysical Data Base, Washington. Study área shown. Larger área used in the calculation of Moho relief and subsequent isostatic gravity anomalies to avoid edge effects (see Fig. 6)

inalterada. Para fins de ilustração, utilizamos a solução para $\mathrm{Te}=20 \mathrm{~km}$, na qual a remoção mais eficiente dos componentes de baixas frequências ressalta as estruturas superficiais. As anomalias isostáticas foram subtraídas das anomalias Bouguer simples numa malha de $0,1^{\circ}(\sim 11 \mathrm{~km}$ nesta latitude) para produzir as anomalias isostáticas residuais (Fig. 7). Nota-se um forte ajuste das anomalias gravimétricas na área setentrional (alto topográfico), enquanto a área meridional de baixo relevo topográfico sofreu pouca mudança. Para esclarecer os detalhes individuais das duas áreas foram utilizadas as anomalias isostáticas residuais na área setentrional
(Fig. 8), tendo-se mantido as anomalias Bouguer simples na área meridional (Fig. 9). Em ambas as áreas, foram construídas malhas de $0,05^{\circ}(\sim 5 \mathrm{~km})$ nas interpolações dos dados gravimétricos irregulares.

INTERPRETAÇ̃̃O OUALITATIVA A inclusão das novas estações (Fig. 4) melhorou sensivelmente a resolução das anomalias gravimétricas locais nas duas áreas do embasamento exposto (Figs. 8 e 9) e da porção intermediária coberta pela Bacia do Paraná (Fig. 7), enquanto as feições regionais permaneceram semelhantes àquelas apresen- 


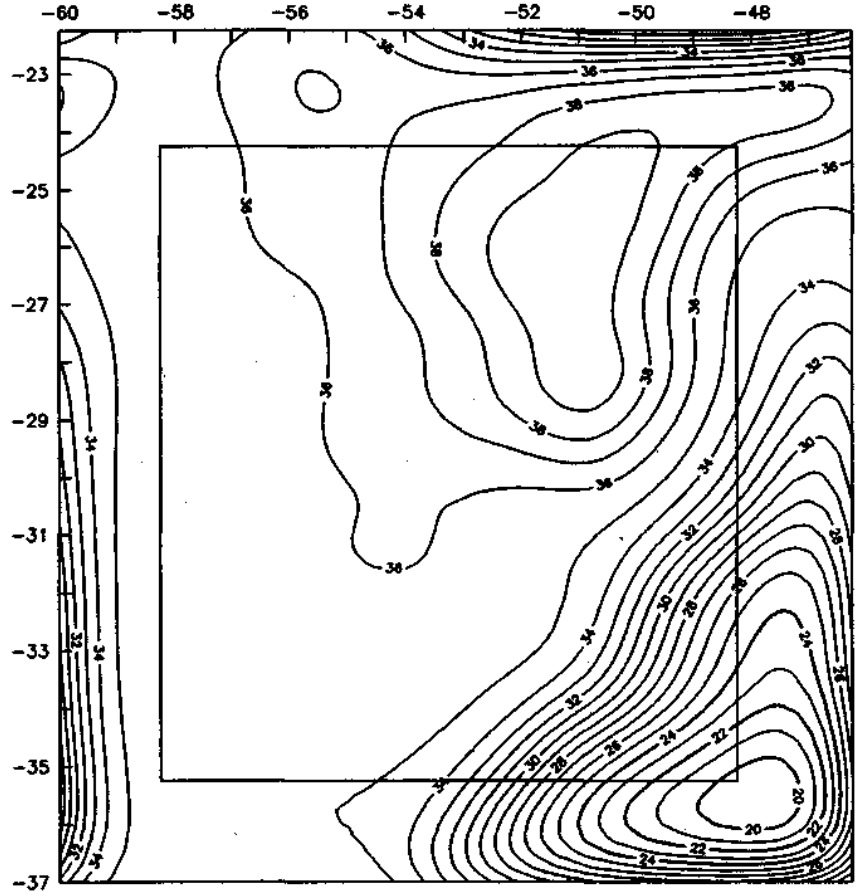

Figura 6 - Relevo da Moho (profundidade em $\mathrm{km}$ ), calculado em função do carregamento topográfico mostrado na figura 5, tendo como espessura elástica efetiva $20 \mathrm{~km}$, e a Moho original a $35 \mathrm{~km}$. Os efeitos de borda não afeiam a área em estudo

Figure 6 - Relief on the Moho (depth in $\mathrm{km}$ ), given the topographic load shown in figure 5 , an effective elastic lithospheric thickness of $20 \mathrm{~km}$, and an original Moho at $35 \mathrm{~km}$. Edge effects do not affect the study área

tadas em estudos anteriores (Mantovani et al. 1989, 1991, Shukowsky et al 1991, Ussami et al. 1993).

A feição regional mais importante corresponde ao gradual aumento da gravidade em direção ao Uruguai (Figs. 4 e 7), a qual permanece no mapa residual de gravidade, embora com amplitude reduzida no caso das anomalias residuais. Diferenças regionais de anomalias isostáticas residuais, devidas a possiveis carregamentos sustentados por placas litosferas rígidas, não podem ser explicadas por um simples modelo de relevo regional mais raso na Moho. Se for o caso, assumindo isostasia de qualquer tipo, a topografia dever ser mais baixa nas áreas de altos gravimétricos regionais, e vice versa. O "excesso de massa" na área meridional somente pode ser explicado por fontes nas regiões subcrustais. Mesmo um evento de underplating, que poderia ter ocorrido durante a abertura do Atlântico Sul quando foi abortado o rift Rio de La Plata, e que, supostamente, adicionou material mais denso na crosta inferior teria o efeito de (1) criar soerguimento na superfície, por simples adição de material com consequente aumento do volume bruto da crosta inferior, ou criar (2) afundamento da crosta (e portanto da superfície) no caso de substitução do material crustal por material mais denso. Em qualquer processo de underplating, as anomalias isostáticas residuais (regionalmente) deveriam ser as mesmas. Sugere-se, aqui, que o excesso de massa sob a área do Cráton Rio de La Plata seja devido as características tectosféricas (parte mantélica) diferentes entre essa área, da Bacia do Paraná, e o embasamento setentrional (ver Jordan 1989, para discussão sobre a tectosfera).

A estrutura do embasamento na região setentrional é bem delineada pelas anomalias gravimétricas isostáticas residuais (Fig. 8), excetuando-se duas feições: 1. alto gravimétrico difuso, com direção $\mathrm{NW}$, que coincide com o enxame de diques do Arco de Ponta Grossa (Mesozóico).
Essa anomalia não pode ser explicada apenas pelo volume dos diques, mas deve ser provavelmente associada a intrusões básicas profundas (como sugerido por Mantovani et al. 1991 e Ussami et al. 1993); na área costeira de Florianópolis, observa-se um gradiente marcante, que não pode mais ser relacionado com o armamento crustal da margem continental, pois esse efeito foi compensado pela remoção das anomalias isostáticas.

As anomalias magnéticas (Fig. 10, dados do DNPM) distinguem claramente os diques Mesozóicos e as margens do Complexo Luis Alves. Na área de Florianópolis, nota-se que há também anomalias magnéticas importantes, alinhadas com a costa e com as anomalias gravimétricas de comprimento de onda, semelhante àquele dos diques de Ponta Grossa, os quais não coincidem com o trena das estruturas do embasamento. Entretanto, existe uma diferença crítica entre as áreas, ou seja, não há significativos afloramentos de diques na região de Florianópolis. Interpretação parcial para esse paradoxo é aquela de se atribuir às coberturas quaternárias a não-observação dos diques numa área significante do litoral. Sugere-se, aqui, que o gradiente gravimétrico positivo de Florianópolis tenha a mesma origem das anomalias de Ponta Grossa: intrusões máficas, ocorridas durante a abertura do Atlântico Sul. Neste cenário, o alto gravimétrico de Pontal do Sul corresponde à simples continuação do alto de Ponta Grossa.

O Bloco Luis Alves apresenta alto gravimétrico relativo aos cinturões deformados que o circundam, devido a presença de granulitos de alta densidade. A proposta continuação dessas fácies para NE, de Morretes (M) para o Complexo Serra Negra (Fig. 2), de Kaul \& Teixeira (1982), é também marcada por uma série de altos independentes, sugerindo que as exposições são parte de lâminas tectônicas do embasamento do Luis Alves, ao invés de constituir protusão contínua. Dentre os cinturões circundantes, os valores mais negativos da anomalia gravimétrica coincidem com os centros de produção de granitos, particulamente os granitos sincinemáticos. Os granitos pós-tectônicos (anorogênicos) são geralmente despojados de anomalias bem definidas, sugerindo natureza mais rasa, quando comparados aos granitos sin-tectônicos. Porém, as anomalias magnéticas mostram divisão do Complexo Luis Alves (anomalias menos ruidosas ao norte), sugerindo que, mesmo se pequenos, os granitos tardios chegaram a diminuir a magnetização da rocha encaixante.

O Cinturão Granitóide Costeiro apresenta-se como um baixo gravimétrico, de acordo com a estrutura proposta por Basei et al. (1991), parcialmente interrompido pelo alto na região de Pontal do Sul. Anomalias semelhantes caracterizam também o Domínio Interno do Dom Feliciano e o Domínio Intermediário, principalmente sobre o Granito de Valsungana. Em termos de idade de granitogênese, petrografia, isótopos e a simples ausência de metassedimentos do Grupo Brusque nos Granitos Costeiros (Basei \& Hawkesworth 1993), prefere-se correlação gravimétrica entre o Domínio Interno e o Cinturão Granitóide Costeiro.

$\mathrm{O}$ alto do Luis Alves continua para SW, em direção à Bacia do Paraná, entretanto; o alto gravimétrico de Tajo encontra-se significativamente deslocado do Domo de Lajes, onde a espessura das coberturas da bacia deve ser drasticamente reduzida. A continuidade desse alto gravimétrico pode estar relacionado ao efeito do embasamento mais próximo da superfície, sugerindo a presença de fragmentos associados ao Luís Alves sob os sedimentos da bacia, como consequência dos esforços cisalhantes da compressão ocorrida no Brasiliano, de forma semelhante ao proposto acima para o Complexo Serra Negra. Alternativamente, pode-se atribuir o alto do Tajo a um corpo alcalino soterrado, de mesma natureza, porém de dimensões mais significativas do que aquelas do corpo associado ao Domo de Lajes. 


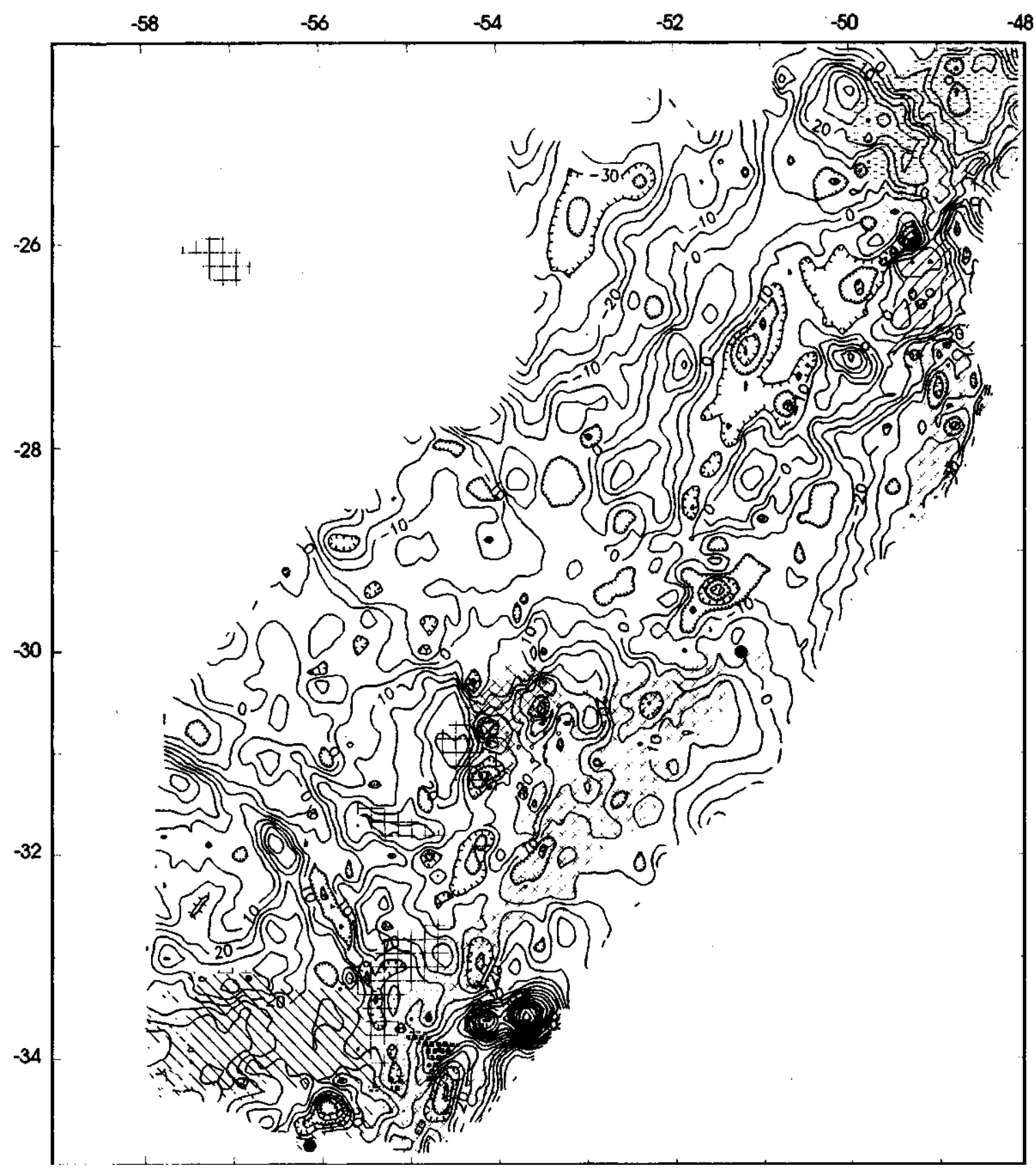

Figura 7 - Anomalias isostáticas residuais (contornos a cada 5 mGal), superpostas à geologia (Fig. 1). Note-se a melhor resolução das anomalias no platô da Bacia do Paraná quando comparadas às anomalias Bouguer simples (Fig. 4) Figure 7 - Isostatic residual Bouguer anomalies (5 mGal) superimposed on the geology (Fig. 1). Notice better resolution of anomalies in the Paraná Basin plateau áreas when compared to the simple Bouguer anomalies (Fig. 4)

$\mathrm{Na}$ área meridional (Fig. 9), a contribuição das estruturas de idade Pré-Brasilíana no Cráton Rio de La Plata é fortemente evidenciada pêlos dados gravimétricos. Adicionalmente, a área cratônica é praticamente plana (Fig. 5) e aparentemente não foi afetada pelo efeito da margem continental. O Cráton Rio de La Plata é geralmente caracterizado por um patamar gravimétrico que cresce em direção aos altos (EW) das áreas de rochas verdes do Arroyo Grande e Paso Severino (Fig. 9). A orientação SSE da margem sudoeste do Terreno Nico Perez (a falha Sarandi dei Yí, FSDY), inferida no mapa de Fragoso César \& Soliani (1984), é confirmada pelo alinhamento de um baixo gravimétrico ali localizado. Esse baixo continua para NW sob as coberturas adjacentes da Bacia do Paraná, onde um conjunto de pares "alto-baixo" gravimétricos muito bem definidos segue um lineamento observado em superfície (traçado por Bossi 1983). Os dados gravimétricos mostram, então, que a área de Arroyo Grande é a exposição mais meridional de um bloco separado no interior do Cráton Rio de La Plata, aqui denominado de Bloco Paso de los Toros; esse bloco é separado do Terreno Nico Perez pela falha Sarandi del Yí, e do Bloco Flórida (que no presente contexto é representado na Fig. 1 pelo Craton Rio de La Plata) através do limite meridional do Cinturão de Rochas Verdes Arroyo Grande.

No interior do Terreno Nico Perez, as áreas granulíticas de Santa Maria Chico e Valentines são evidenciadas por altos gravimétricos que contrastam com os baixos dos 


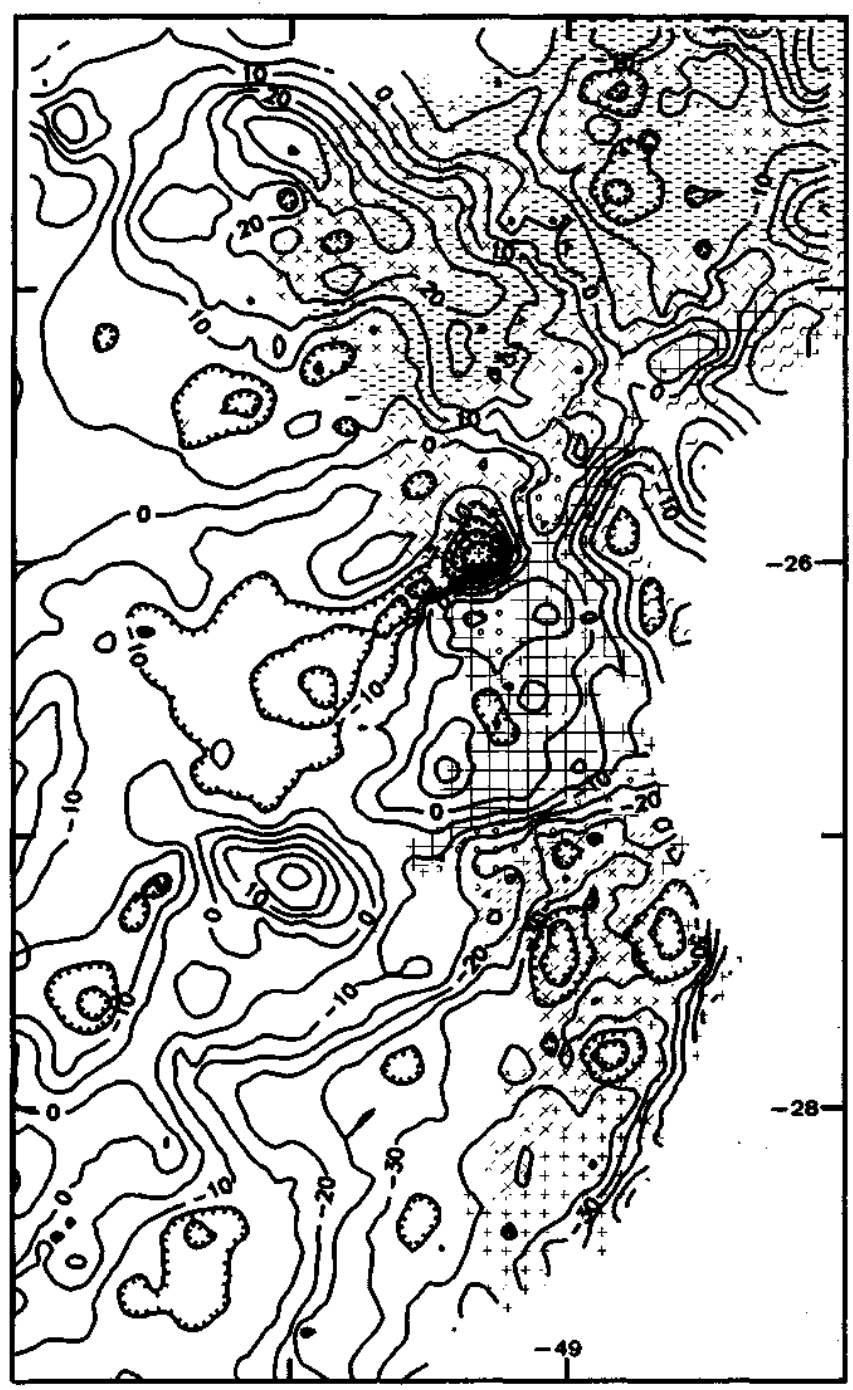

Figura 8 - Anomalias isostáticas residuais sobre a área setentrional do embasamento

Figure 8- Residual isostatic anomalies over the northerii basement área

gnaisses de Bagé. A tendência dessas anomalias é parcialmente interrompida pela Falha Transcorrente de Ibaré, mas a tendência do alto devido aos granulitos, que se propaga na porção ocidental, sugere que o Terreno Vacacaí seja sobreposto a granulitos do Terreno Nico Perez, o que é evidenciado pela ocorrência de xenólitos granulíticos (Fragoso César 1991).

Assim como para a área setentrional, o Cinturão Dom Feliciano é caracterizado por anomalias alinhadas com as estruturas principais. $\mathrm{O}$ alto, em correspondência à Faixa Tijucas, no Rio Grande do Sul, continua pelo menos em direção às exposições mais setentrionais do Grupo Lavalleja no Uruguai; os baixos, associados com os granitos do Batólito de Pelotas, continuam na zona central do Cinturão Dom Feliciano no Uruguai, limitado a oeste pela Dorsal de Canguçu e pela Zona de Cisalhamento Sierra Ballena (ZCDC e ZCSB). Note-se que, no Rio Grande do Sul, o mínimo gravimétrico em correspondência do eixo ocidental do Batólito Pelotas está acima dos granitos tardi-tectônicos e se estende também em direção ao Batólito Encruzilhada do Sul (ES), sugerindo que: (1) os monzogranitos tardi-tectônicos (granitos sin-cinemáticos do Arco II de Fernandes et al. 1990 e 1992; os granitos Dom Feliciano, Figs. 3 e 8) são mais importantes em termos volumétricos do que os leucogranitos nessa região, e (2) os granitos tardios do Ciclo Brasiliano formam efetivamente um único corpo em profundidade, para ambas as unidades.

A forte anomalia positiva da Lagoa Mirim se alinha ENE, atravessando a tendência do Dom Feliciano com a superposição de lavas básicas cretácicas, relacionadas com a abertura do Atlântico Sul. A anomalia é, portanto, mais provavelmente devida a intrusão de corpo básico ocorrida durante o processo de rifting. Note-se que essa anomalia é desviada para SSW e cessa na Zona de Cisalhamento Sierra Ballena (ZCSB), e que, para SW, a Bacia Santa Lúcia (Cretácica?) é caracterizada por uma anomalia negativa, presumivelmente relacionada às coberturas sedimentares. Sugere-se que a SBSZ atuou como bloqueio na porção ocidental da transcorrência ocorrida durante o fendilhamento e, portanto, atuou como barreira para o desenvolvimento de significativo magmatismo basáltico na porção ocidental.

CORRELAÇÕES E NÃO-CORRELAÇÕES TECTÔNICAS NORTE-SUL A continuação do Cráton Rio de La Plata (como é definido no Uruguai) para dentro do Brasil não é sustentada pela gravimetria. Pelo contrário, na margem setentrional do cráton, a Falha Sarandí dei Yí, no Uruguay, continua embaixo da cobertura da Bacia do Paraná, rumo NW para a Argentina. $\mathrm{O}$ antigo Terreno Nico Perez, que foi fortemente reativado durante o Ciclo Brasiliano (a possível margem reativada do cráton) continua para dentro do Rio Grande do Sul, na área de Bagé e Dom Pedrito. É sugerido, aqui, que esse terreno formou o antepaís durante a evolução do Cinturão Dom Feliciano no Uruguai e no Rio Grande do Sul. Qualquer ligação genética entre o Terreno Nico Perez e o Cráton Rio de La Plata é necessariamente especulativa, se não existirem estudos mais detalhados como, por exemplo, datações radiométricas e estudos petrogenéticos.

Embora estudos anteriores mostrem uma continuação das anomalias gravimétricas negativas associadas aos vários granitos do Cinturão Dom Feliciano (Figs. 7, 8 e 9), o que sugere a continuação física dessa faixa desde Santa Catarina até o Uruguai, existem vários contrastes geológicos e geofísicos, entre as duas regiões:

B asei \& Hawkesworth (1993) sugerem (por meio de estudos dos isótopos) que o anteriormente denominado Domínio Interno do Cinturão Dom Feliciano, em Santa Catarina (Basei 1985), contendo os granitos foliados e granitos tardios de Pedras Grandes, não formam nenhuma associação com os demais Domínios. O Domínio Interno faz parte de um arco magmático relativamente recente comparado ao magmatismo representado pelas granitos sinteetônicos no Domínio Intermediário (Suítes Valsungana e Guabiruba), que chocou-se com as demais regiões no final do Ciclo Brasiliano (o limite pode ser localizado pela Falha Major Gercino). Assim, o Domínio Interno é provavelmente associado ao Domínio Granitóide Costeiro, como acima descrito no contexto das anomalias gravimétricas. Para esses autores, ò Cinturão Dom Feliciano, em Santa Catarina, é composto por vários "terrenos suspeitos", que se uniram somente no final do Ciclo Brasiliano, ao longo de falhas transcorrentes.

Os metassedimentos do Cinturão Dom Feliciano, supostamente da margem continental pré-colisional, representam características distintas; em Santa Catarina, para anomalias negativas, relacionadas em parte aos granitóides sin-tectônicos, e, no Rio Grande do Sul, pelas anomalias positivas devidas a altos do embasamento pré-Brasiliano (e.g., os Gnaisses Encantadas).

E dificil traçar qualquer feição gravimétrica do Cinturão Dom Feliciano de Santa Catarina ao Rio Grande do Sul. As anomalias isostáticas residuais situam-se na porção orien- 


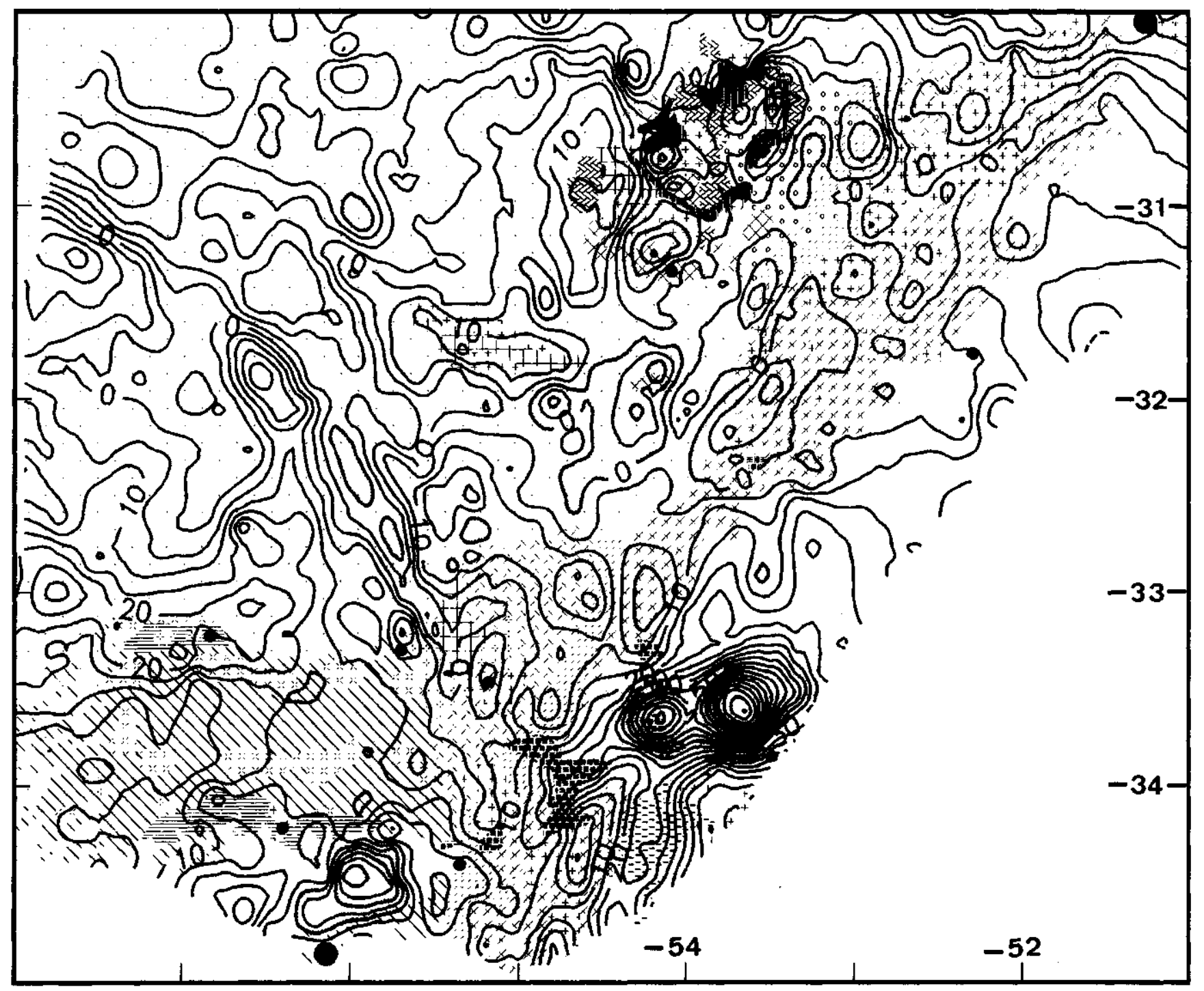

Figura 9 -Anomalias isostáticas residuais sobre a porção meridional do embasamento Figure 9 - Residual isostatic anomalies over the southern basement área

tal de Porto Alegre e não sobre o Batólito Pelotas, como sugerido em trabalhos anteriores baseados nas anomalias Bouguer simples (Hallinan et al. 1993, Shukowsky et al. 1991). Pelo fato de as anomalias negativas no Cinturão Dom Felíciano representarem granitos distintos nas duas áreas, granitos pré/sin-tectonicos (Valsungana etc.), em Santa Catarina, e granitos tardios, no Rio Grande do Sul (Dom Feliciano e Encruzilhada do Sul), não é correto utilizar a continuidade das anomalias negativas para demonstrar a continuidade física do Cinturão Dom Feliciano, entre Santa Catarina e Rio Grande do Sul. E tentativamente proposto, aqui, que o anteriormente denominado Domínio Interno, em Santa Catarina, não aflora ao sul de Santa Catarina, mas é o responsável pêlos gradientes negativos da porção sul da Lagoa dos Patos e, possivelmente, ao sul do Chuí.

Torna-se clara, pela figura 7 , a continuação meridional das estruturas (1) do Complexo Luís Alves, (2) dos granitos foliados do Maciço de Curitiba, de (3) uma provável feição do Cinturão Ribeira, sendo que todos terminam numa latitude de aproximadamente $-29^{\circ}$, cortados por anomalia negativa EW. As anomalias negativas do Maciço de Curitiba, extinguem-se entre as anomalias positivas do Luis Alves e do Ribeira. Na Serra Gaúcha, a norte e oeste de Porto Alegre, afloram os riolitos do magmatismo mesozóico, numa linha aproximadamente coincidente com a anomalia negativa EW. E possivel que uns granitos Mesozóicos estejam associados aos riolitos, causando os baixos gravimétricos. Neste cenário, há continuação do Cinturão Ribeira até o Escudo Sul-Rio-Grandense (como sugerido por Fragoso César 1991 e Soares et al. -1993).

Finalmente, deve-se considerar que a gravimetria é simplesmente um dos vários métodos indispensáveis na investigação de correlações regionais.

Agradecimentos Os autores agradecem ao Dr. M.A.S. Basei, pelas frutíferas discussões sobre a geologia da área. Aos Dr. L.A.D. Fernandes e ao geólogo A.C.B.C. Vasconcellos, pelas informações geológicas. Aos Sr. E.M. Leite, T.M. Mouallen e A.D. Villares Neto, pela colaboração nas atividades de campo, e à Dra. N. Ussami, pelo programa de cálculo das anomalias isostáticas, aqui utilizado. Aos revisores do artigo pelas sugestões e críticas oportunas. Este trabalho foi realizado com 0 imprescindível apoio financeiro da FAPESP e CNPq. 


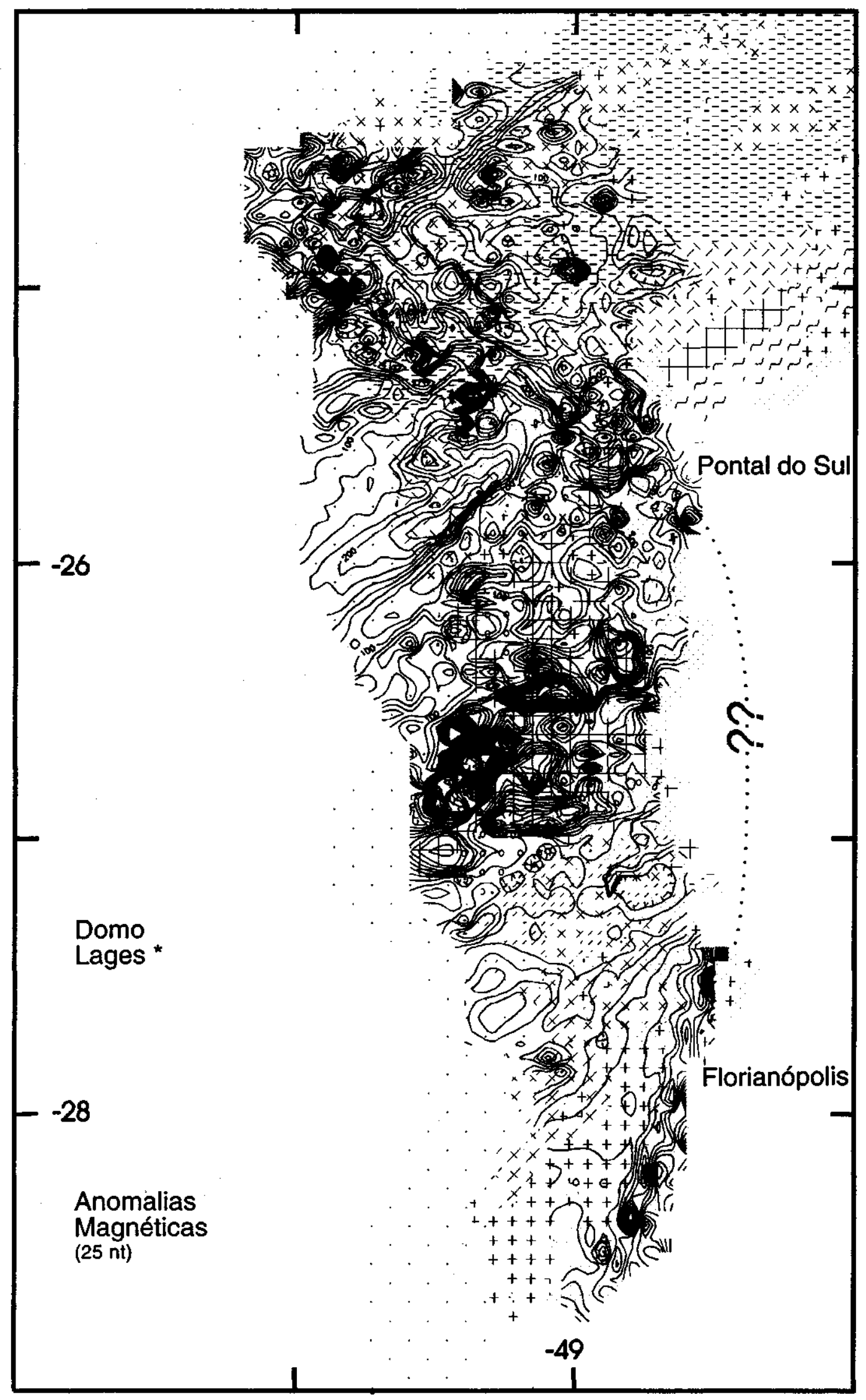

Figura 10 -Anomalias magnéticas de campo total sobre a área setentrional do embasamento (contornos de 25 nT sobre uma malha de $0,05^{\circ}$ )

Figure 10 - Total magnetic anomalies over the northern basement area. ( $25 \mathrm{nT}$ contours on a 0.05 degree grid) 


\section{REFERÊNCIAS BIBLIOGRÁFICAS}

ALMEIDA, F.F.M.; AMARAL, G.; CORDANI, U.G.; KAWASHITA, K. 1973. The Precambrian evolution of the South American cratonic margin, South of Amazon. In: NAIRN, A.E.M.; KANES, W.K.; STEHLI, F.G. eds. The Ocean Basins andMargins. New York, New York. v. 1, p. 411-446.

AWDZIEJ, J.; PORCHER, C.A.; SILVA, L.C. 1986. Mapa Geológico do Estado de Santa Catarina escala 1:500.000. Local, DNPM.

BANKS, R.J.; PARKER, R.L.; HUESIS, S.P. 1977. Isostatic compensation on a continental scale: Local versus regional mechanisms. J. $R$. Astron. Soe., 51:431-452.

BASEI, M.A.S. 1985. O Cinturão Dom Feliciano em Santa Catarina. São Paulo. 190 p. (Tese de Doutorado, IG-USP).

BASEI, M.A.S.; SIGA JÚNIÇR, O.; MACHIAVELLI, A.; MANCINI, F. 1991. Evolução tectônica dos terrenos entre os cinturões Ribeira e Dom Feliciano (Paraná-Santa Catarina). Rev. Bros. Geoc., 22(2):216-221.

BASEI, M.A.S. \& HAWKESWORTH, C. 1993. O magmatismo do Cinturão Dom Feliciano (Santa Catarina) e sua importância no estabelecimento das principais descontinuidades crustais da região SulBrasilelra. In: SIMP. INTERN. DEL NEOPROTEROZOICOCAMBRICO DE LA CUENCA DEL PLATA, 1. Lãs Palomas-Minas, 1993. Boletim de Resumos Expandidos... Lãs Palomas-Minas, Uruguay, DINAMIGE. resumo $\mathrm{n}^{*} 41$.

BECHTEL, T.D.; FORSYTH, D.W.; SHARPTON, V.L.; GRIEVE, A.F. 1990. Variations in effective elastic thickness of the North American lithosphere. Nature, 343:636-638.

BITENCOURT, M.F.; HACKSPACHER, P.C.; STOLL, L.V. 1989. A Zona de Cisalhamento Major Gercino - Santa Catarina. In: SIMP. NAC. EST. TECT., 2. Fortaleza, 1989. Fortaleza, SBG. Boi 11, p. 214-215.

BRITO NEVES, B.B. \& CORDANI, U.G. 1991. Tectonic evolution of South America during the Late Proterozoic. Precambrian Rés., 53:23-40.

BIONDI, J.C.; CAVA, L.T.; SOARES, P.C. 1989. Mapa Geológico do Estado de Paraná, Escala 1:650.000. Curitiba, DNPM

BOSSI, J. 1983. Breve resena sobre el conocimento geológico dei Escudo Predevoniano en Uruguay. ZbL Geol. Palâontol, I(3/4):417-429.

BOSSI, J. \& CAMPAL, N. 1992. Magmatismo y tectônica transcurrente durante el Paleozóico Inferior en Uruguay. In : GUTIERREZ MARCO, J.G.; SAAVEDRA, J.; RABANO, I. eds. Paleozóico Inferior de Ibero-América. Extremadura, Universidade de Extremadura.

CAMPANHA, G.A.C.; BISTRICHI, C.A.; ALMEIDA, M.A. 1987. Considerações sobre a organização, litoestratigráfica da Faixa de Dobramentos Apiaí. In: SIMP. BRÁS. GEOL., 3. Curitiba, 1987. Atas... Curitiba, SBG. 2:725-742.

CORDANI, U.G. \& SOLIANI, E Jr. 1990. Idades K-Are Rb-Sr das "Islãs Cristaíinhas" de Rivera e Áceguá (Uruguay e Rio Grande do Sul, Brasil) e seu enquadramento no contexto geotectônico regional. An. Acad. bras. Ci., 62(2): 145-156.

DALLA SALDA, L.; BOSSI, J.; CINGOLANI, C. 1988. The Rio de Ia Plata Cratonic Region of SW Gondwanaland. Episodes, 11(4):263269

FERNANDES, L.A.D.; TOMMASI, A.; PORCHER, C.C. 1990. Esboço estrutural de parte do Batólito Pelotas, Região de Quitéria-Capivarita. Acta Geol. Leopold., 30:117-138.

FERNANDES, L.A.D; TOMMASI, A.; PCRCHER, C.C. 1992. Deformation patterns in the southern Brazilian branch of the Dom Feliciano Belt: A reappraisal. J. South Am. Earth Sei., 5(1):77-96.

FERRANDO, L.A. \& FERNANDEZ, R.N. 1971. Esquema tectônico cronostratigráfico dei Predevoniano en Uruguay. In: CONGR. BRAS. GEOL., 25. São Paulo, 1971. Anais... São Paulo, SBG. v. 1, p. 199-210.

FORSYTH, D.W. 1985. Subsurface loading and estimates of the flexural rigidity of continental lithosphere. J. Geophys. Rés., 90(B14):1262312632 .

FRAGOSO CÉSAR, A.R.S. 1980. O Cráton Rio de Ia Plata e o Cinturão Dom Feliciano no Escudo Uruguaio-Sul-Riograndense. In: CONGR. BRAS. GEOL, 31. Curutiba, 1980. Anais... Curitiba, SBG. v. 5, p. 2879-2892.

FRAGOSO, A.R.S 1991. Tectônica de Placas no Ciclo Brasiliano: As Orogenias dos Cinturões Dom Feliciano e Ribeira no Rio Grande do Sul. São Paulo. 367 p. (Tese de Doutorado, IG-USP).

FRAGOSO CÉSAR, A.R.S. \& SOLIANI, E., Jr. 1984. Compartimentacão Tectônica do Cráton do Rio de Ia Plata. In: CONGR. BRAS. GEOL., 33. Rio de Janeiro, 1984. Anais... Rio de Janeiro, SBG. p. 2,426-2434

FRAGOSO CESAR, A.R.S.; FIGUEIREDO, M.C.H.; SOLIANI, E., Jr.; FACCINI, U.F. 1986. O Batólito Pelotas (Proterozóico Superior/EoPaleozóico) no escudo do Rio Grande do Sul. In: CONGR BRAS. GEOL., 34. Goiânia, 1986. Anais... Goiânia, SBG. v. 3, p. 13221337.

FRAGOSO CÉSAR, A.R.S.; MACHADO, R.; RIFAS, C.G. 1987. Observações sobre o Cinturão Dom Feliciano no Escudo Uruguaio e Correlacões com o Escudo do Rio Grande do Sul. In: SIMP. SUL-BRAS. GEOL., 3. Curitiba, 1987. Atas... Curitiba, SBG. v. 2, p. 791-809.

HALLINAN, S.; SHUKOWSKY, W.; MANTOVANI, M.S.M. 1993. Estruturação do embasamento Précambrico da região Sul do Brasil e
Uruguai: Novos modelos resultantes de densifícação gravimétrica. In: SIMP. INTERN. DEL NEOPROTEROZOICO-CAMBRICO DE LA CUENCA DEL PLATA, 1. Lãs Palomas-Minas, 1993. Boletim de Resumos Expandidos... Lãs Palomas-Minas, Uruguay, DINAMIGE. resumo $\mathrm{n}^{\text {fi }} 31$.

HARTMANN, L.A.; SILVA L.C. ORLANDI FILHO, V. 1979. Complexo Granulitico de Santa Catarina - Descrição e implicações genéticas. Acta Geol. Leopold., 3: 93-111.

HARTMANN, L.A.; NÄRDI, L.S.; CUPERTINO, J.A. 1979. A cataclase nos granulitos de Luis Alves (Santa Catarina). Acta Geol. Leopold. 3:29-43.

HASUI, Y; CARNEIRO. C.D.R.; COIMBRA, A.M. 1975. The Ribeira folded belt. Rev. Bras, Geoc., 5(4):257-266.

JANASI, V. A. \& ULBRICH, H.H.G.J. 1991. Late Proterozoic granitoid magmatism in the state of São Paulo, southeastern Brazil. Precambrian Rés., 51:351-374.

JANASI, V.A. \& ULBRICH, H.H.GJ. 1992. Inventário Bibliográfico de Granitos do Estado de São Paulo. Boi. IG-USP, Publ. Esp., $11: 253 \mathrm{p}$

JORDAN, T. 1989. Some speculations on continental evolution. In: CrustMantle Recycling ai Convergent zones. In: HAT, S.R. \& GÜLLEN, L. eds. Kluwer Acad. Publ. p. 259-276.

KARNER, G.D. \& WATTS, A.B. 1982. On isostasy at Atlantic-Type Continental Margins. J. Geophys. Rés., 87(B4):2923-2948.

KAUL, PFT \& TEIXEIRA, W. 1982. Archean and Early Proterozoic complexes of Santa Catarina, Paraná and SP States, SSE Brazil: An outline of their geological evolution. Rev. Bras. Geoc., 12(1-3):172-182.

MACHIAVELLI, A. 1991. Os Granitóides Deformados da Região de Piên Paraná): um Provável Arco Magmatico do Proterozóico Superior. São Paulo. 89 p. (Dissertação de Mestrado, IG-USP).

MANTOVANI, M.S.M.; SHUKOWSKY, W.; BASEI, M.A.S.; VASCONCELLOS, A.C.B.C. 1989. Modelo gravimétrico das principais descontinuidades crustais nos terrenos pré-cambrianos dos Estados do Paraná e de Santa Catarina. Rev. Bras. Geoc., 19(3):367-374

MANTOVANI, M.S.M.; VASCONCELLOS, A.C.B.C.; SHUKOWSKY, W. 1991. Global Geoscience Transect 4: Brusque Transect from Atlantic Coast to Bolivian Border, Southern Brazil. Washington, AGU. p. 1-20. (Spec. Publ)

NARDI, L.V.S. \& HARTMANN, L.A. 1979. O complexo Granulitico Santa Maria Chico do Escudo Sul-Rio-Grandense. Acta Geol. Leopold., 3(6):45-76

PARKER, R.L. 1972. The rapid calculation of potential anomalies. Geophys. J. R. Astron. Soe. 31:447-455.

PASSARELLI, C.R.;BASEI, M.A.S.; CAMPOS NETO, M.C. 1993 Caracterização geométrica e cinemática da zona de cisalhamento Major Gercino e sua importância na compartimentacão dos terrenos pré-cambrianos de Santa Catarina. In: SIMP. INTERN. DEL NEOPROTEROZÓICO-CAMBRICO DE LA CUENCA DEL PLATA, 1. Lãs Palomas-Minas, 1993. Boletim de Resumos Expandidos... Lãs Palomas-Minas, Uruguay, DINAMIGE. resumo n* 23.

PICADA, R.S. 1971. Ensaio sobre a tectônica do Escudo Sul-RioGrandense. Caracterização dos sistemas de falhas. In: CONGR. BRAS. GEOL., 25. São Paulo, 1971. Anais... São Paulo, SBG. v. 1, p. 167-191.

PORADA, H. 1979. The Damara-Ribeira orogen of the Pan-African/ Brasiliano Cycle in Namibia (South West Africa) and Brazil as interpreted in terms of continental collision. Tectonophysics, 57:237-265

PORADA, H. (1991) Pan-African Rifting and Orogenesis in Southern to Equatorial Africa and Eastern Brazil. Precambrian Rés., 44:103-136.

PRECIOZZI, F.; SPOTURNO, J.; HEINZEN, W. 1980. Carta GeoEstructural dei Uruguay ai 1:2.000.000. Montevideo, Instituto Geológico dei Uruguay.

SANTOS, E.L.; RAMGRAB, G.E.; MACIEL, L.A.; MÕSMANN, R.; ROISENBERG, A.; VILLWOCK, J.A.; TOMAZELLI, L.J.; WILDNER, W. 1989. Mapa Geológico do Estado de Rio Grande do Sul, Escala 1:1.000.000. DNPM.

SERVICIO GEOGRÁFICO MILITAR DEL PARAGUAY 1973. Carto Gravimétrica Provisória de Ia Republica dei Uruguay. SGM.

SHUKOWSKY, W; BLITZKOW, D.; SÁ, N.C.; SURITA, C.A. 1987. A Correção de Relevo na Região de Grande São Paulo. Rio de Janeiro, SBGf. v 1, p. 94

SHUKOWSKY, W; MANTOVANI, M.S.M.; HALLINAN, S. 1993. A espessura elástica do segmento litosferiço Sul do Brasil - Uruguai: Uma análise da coerência entre os sinais gravimétrico e topográfico. In: SIMP. INTERN. DEL NEOPROTEROZÓICO-CAMBRICO DE LA CUENCA DEL PLATA, 1. Lãs Palomas-Minas, 1993. Boletim de Resumos Expandidos... Lãs Palomas-Minas, Uruguay, DINAMIGE. resumo $n^{9} 32$.

SHUKOWSKY W; VASCONCELLOS, A.C.B.C. MANTOVANI, M.S.M. 1991. Estruturacão dos terrenos pré-Cambrianos da região sul do Brasil e oeste do Uruguai: Um estudo por modelamento gravimétrico. Rev. Bras. Geof., 9(2):275-287. 
SOARES, P.C:; ASSINE, M.L. VAZ CHAVES, N. 1993. De Ia Província orogénica ai Craton estable: Historia neoproterozoica y eopaleozoica de Ia parte centro-meridional de America dei Sur. In: SIMP. INTERN. DEL NEOPROTEROZÓICO-CAMBRICO DE LA CUENCA DEL PLATA, 1. Lãs Palomas-Minas, 1993. Boletim de Resumos Expandidos... Lãs Palomas-Minas, Uruguay, DINAMIGE. resumo $n^{2} 10$

SOLIANI, E., Jr. 1986. Os Dados Geocronolópicos do Escudo Sul-RioGrandense e suas Implicações de Ordem Tectônica. São Paulo. 495 p. (Tese de Doutoramento, IG-USP)

USSAMI, N.; CÔGO de SÁ, N.; MOLINA, E.C. 1993. Gravity Map of Brazil 2. Regional and Residual Isostatic Anomalies and Their
Correlation With Major Tectonic Provinces. J. Geophys. Rés., 98(B2):2199-2208.

ZALÁN, P. V; WOLFF, S.; CONCEICÃO, J.C.; ASTOLFI, M.A.M.; VIEIRA, I.S.; APPI, V.T.; ZANOTTO, O.A.; MARQUES, A. 1988. Tectonic and sedimentation of the Paraná basin. In: SIMP. GONDWANA, 7. São Paulo, 1988. Anais... São Paulo. v. l, p. 35.

MANUSCRITO A796

Recebido em 13 de setembro de 1993 Revisão do autor em 31 maio de 1994 Revisão aceita em 16 de junho de 1994 